\title{
Influence of Harvest Date and 2C Storage on Floral Development of Dutch-grown Astilbe
}

\author{
Gwendolyn H. Pemberton ${ }^{1}$ and A.A. De Hertogh ${ }^{2}$ \\ Department of Horticultural Science, Box 7609, North Carolina State University, Raleigh, NC27695-7609
}

Additional index words. false spiraea, herbaceous perennial, morphology, plant maturity, scanning electron microscopy

\begin{abstract}
Dutch-grown 'Deutschland', 'Fanal', and 'Rheinland' Astilbe, harvested 1 Nov. 1992 and shipped to the United States, were dissected to determine the stage of floral development after $0,2,4,6,8,10,12$, or 15 weeks of $2 \mathrm{C}$ storage. Astilbe crowns were also planted after 15 weeks of $2 \mathrm{C}$ storage and floral development was determined after 1, 2, or 3 weeks of greenhouse forcing. On arrival, multiflower inflorescences were clearly visible. A pattern of abortion and reinitiation occurred during 2C storage. Floral development was markedly repressed when ecodormancy was imposed, but development resumed during greenhouse forcing. During the observational period, floral organ numbers were variable, and morphological abnormalities were observed. In a second experiment, physiological maturity of the crowns was evaluated by harvesting crowns of 'Bumalda', 'Europa', 'Federsee', and 'Rheinland' on 15 Sept., 1 Oct., 15 Oct., 1 Nov., and 15 Nov. in The Netherlands. Optimal harvest period was from 1 Oct. to 1 Nov., depending on the cultivar. Crowns harvested before this period were physiologically immature. Crowns harvested during the 4-week window produced the highest overall plant quality and performed as physiologically mature crowns. Astilbe crowns harvested after the 4-week window produced plants with lower forcing qualities and were determined to be beyond the optimal physiological state for forcing.
\end{abstract}

Astilbe are field-grown in The Netherlands and are harvested from 1 Oct. to 1 Dec. (T. Ruigrok, personal communication). The decision to harvest the crowns usually depends on seasonal weather conditions. One major problem associated with forcing Astilbe has been flower abortion. Crowns harvested early in the season may not be physiologically mature or may be juvenile in nature. A delayed harvest may result in crowns that are overmature for forcing.

The physiological state of some flower bulbs at harvest can be attributed to preharvest temperatures (De Hertogh and Le Nard, 1993). Either immature bulbs form no flowers or the flowers readily abort. Mahlstede and Fletcher (1960) emphasized the importance of plant maturity for certain perennials and found that, when immature plants were harvested, they often either deteriorated in storage or rotted. They proposed that the accumulation and ratios of starches, sugars, enzyme systems, celluloses, and endogenous hormone systems were integral in determining whether a plant would store properly or overwinter.

Many methods have been proposed to measure a plant's maturity. One important method is bulb size (Hartsema, 1961). The size chosen to determine maturity, however, can vary with the production location, genus, species, and sometimes cultivar. With herbaceous perennials, the number of nodes and crown fresh weight have been used as maturity markers (Bernier et al., 1981). Mahlstede (1956) used 'McGredy's Ivory' hybrid tea rose (Rosa odorata) and mixed hollyhocks (Alcea rosea) to demonstrate the importance of plant maturity for storage life, survival, and subsequent growth. He found that when harvesting was delayed from 24 Sept. to 29 Oct.,

\footnotetext{
Received for publication 4 Jan. 1993. Accepted for publication 2 June 1993. A portion of a thesis submitted by G.H.P. as partial fulfillment of the requirement for the MS degree at North Carolina State Univ. We gratefully acknowledge the financial support of the Dutch Bulb Exporters Association, Hillegom, The Netherlands, and the Jac. Th. de Vroomen Bulb Co. of Lisse, The Netherlands, for the special handling of the crowns. Use of trade names does not imply endorsement of the products named nor criticism of similar ones not named. The cost of publishing this paper was defrayed in part by the payment of page charges. Under postal regulations, this paper therefore must be hereby marked advertisement solely to indicate this fact.

${ }^{1}$ Graduate student.

${ }^{2}$ Professor.
}

the field survival of spring-planted stocks increased. Storage performance and subsequent field survival were directly related to hardening or maturation initiated by a killing frost.

The mature Astilbe inflorescence (Fig. 1) is comprised of small and inconspicuous individual florets (Bailey, 1935; Chittenden

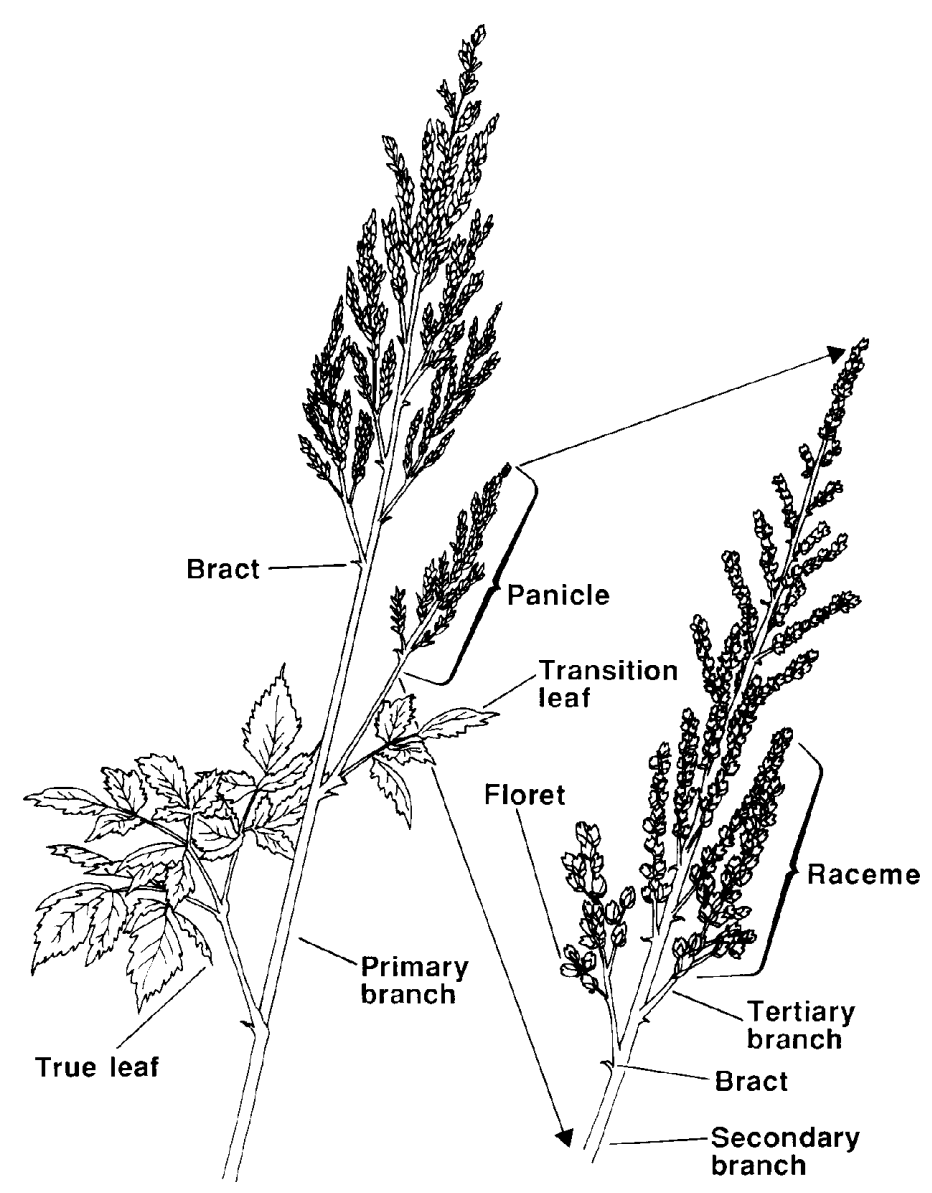

Fig. 1. Morphology of the Astilbe inflorescence, a panicle of racemes with florets borne on tertiary branches. 
and Synge, 1956; Liberty Hyde Bailey Hortorium, 1976; Radford et al., 1964). Many florets, on a spike or a many-branched panicle, comprise the bracteate inflorescence. Flowers are perfect or dioecious with a small five-lobed calyx. There are usually four to five petals with eight or ten stamens. There can be either two or three pistils, either separate or united. There are no more than two or three carpels with many seeds in the dehiscent follicles.

The objectives of this study were to record the stages of floral development of Astilbe during storage for spring forcing and to determine if crown maturity, as affected by harvesting date, influenced subsequent floral development.

\section{Materials and Methods}

Experiment 1. All Astilbe crowns were grown under field conditions in The Netherlands. 'Deutschland' (white), 'Fanal' (red), and 'Rheinland' (pink) crowns were harvested on 1 Nov. 1991. They were immediately cut into 125 single-eyed crowns, washed, and given a hot water treatment for $2.5 \mathrm{~h}$ at $43 \mathrm{C}$ to control nematodes. According to Latta and Doucette (1932), 44C vapor heat reduced the number of days for Astilbe to flower and released them from endodormancy. Post (1959) demonstrated that crowns could be treated with $44 \mathrm{C}$ vapor heat and stored at $2 \mathrm{C}$ before forcing to reduce the forcing time similarly.

Crowns were subsequently packed in nonperforated polyethylene bags with moist peat and placed in cardboard boxes. The boxes were air-freighted to Raleigh, N.C., on 20 Nov. 1991; they arrived 23 Nov. 1991 and immediately were placed in a cooler at 2C and $90 \%$ relative humidity. During storage, the crowns were kept moist at all times.

Apical meristems were dissected from 10 crowns after $0,2,4$, $6,8,10,12$, or 15 weeks of cold storage. Plants that received 15 weeks of $2 \mathrm{C}$ were also sampled 1,2, or 3 weeks after planting and forcing in a greenhouse.

Before dissection, crowns were thoroughly washed. Apical meristems were isolated using a light microscope. Dissections were performed with the plant tissue submerged in distilled water in a petri dish. Isolated meristems were immediately placed in formalin acetic acid for $24 \mathrm{~h}$ or more and then dehydrated in a series of ethanol washes at the following concentrations: $30 \%, 50 \%$, $70 \%$, and $95 \%$. When necessary, tissue was stored in $70 \%$ ethanol. Tissue was further dehydrated in three changes of $100 \%$ ethanol, $1 \mathrm{~h}$ each at room temperature. Meristems were critical-point dried using carbon dioxide in a critical-point dryer (Samdri PVT-3B; Tousimis Research Co., Rockville, Md.) and then sputter-coated in a sputter coater (Technics Hummer V; Anatech Ltd., Alexandria, Va.) with $60 \mathrm{~nm}$ of gold-palladium from four different angles. Meristems were analyzed for floral development using a scanning electron microscope (SEM) (model 505T; Philips, Eindhoven, The Netherlands).

Plants forced in the greenhouse before dissection were planted in a peatlite medium (Sunshine Mix No. 4; Fisons Horticulture, Vancouver, B.C.). Three single-eyed crowns were planted per 15$\mathrm{cm}$ (1.77-liter) standard pot. During forcing, greenhouse temperatures ranged from 18 to $20 \mathrm{C}$ during the day and 16 to $18 \mathrm{C}$ during the night. Natural irradiance and photoperiods at lat. $35^{\circ} 47^{\prime} \mathrm{N}$ were used. The average daylength during forcing was as follows: $12 \mathrm{~h}$, March; 13 h, April; 14 h, May; and 14.5 h, June. Initially, the planting medium was watered once a week. Once foliage appeared, the medium was watered when dry to the touch. Six grams of a slow-release fertilizer (Osmocote 14-6.2-11.6, Grace-Sierra Chemical Co., Allentown, Pa.) per pot was applied to the planting medium after shoots grew 5 to $7.5 \mathrm{~cm}$.
Experiment 2. 'Bumalda' (white), 'Europa' (light rose), 'Federsee' (pink), and 'Rheinland' (pink) were grown under field conditions in The Netherlands. Crowns of each cultivar were harvested on 15 Sept., 1 Oct., 15 Oct., 1 Nov., and 15 Nov. 1991. Crowns harvested before $15 \mathrm{Nov}$. were stored at $2 \mathrm{C}$ until the final harvest. After the final harvest, crowns were cut into single-eyed pieces, washed, and given a hot water treatment for $2.5 \mathrm{~h}$ at $43 \mathrm{C}$ to control nematodes. Crowns were packed and shipped as in Expt. 1.

After 12 weeks of cold storage, crowns were planted on $18 \mathrm{Feb}$. 1992 in Sunshine Mix No. 4. Three single-eyed crowns were used in a $15-\mathrm{cm}$ (1.77-liter) standard pot. The experiment was a randomized complete-block design consisting of five replications per treatment. There were five blocks representing the five harvest dates. One week after planting, each pot was drenched with $236 \mathrm{ml}$ of etridiazole + thiophanate-methyl (Grace-Sierra Chemical Co., Allentown, Pa.) at $0.59 \mathrm{~g} \cdot \mathrm{liter}^{-1}$ to prevent root rot. Greenhouse forcing conditions for Expt. 2 were the same as those previously described for Expt. 1.

Experimental variables recorded. The following variables were recorded: 1) days to market stage (MS) — the number of days from planting to the date that the first floret was fully open; 2) days to full flower (FF) - the number of days from planting to the day that $90 \%$ of the florets were open; 3) total plant height (TPH) - the height of the plant as measured from the top of the pot to the highest part of the plant; 4) inflorescence height (IH) - the height of the primary inflorescence branch as measured from the top of the pot to the highest part of the inflorescence; 5) leaf height ( $\mathrm{LH}$ - - the height of the leaf canopy measured from the top of the pot to the top of the canopy; 6) inflorescence length (IL) — the length of the inflorescence as measured from the leaf axil of the highest secondary inflorescence to the tip of the primary inflorescence; 7) inflorescence width (IW) - the width of the inflorescence measured at the widest portion of the primary branch; 8) plant diameter (PD) - the diameter of the leaf canopy of the plants in one pot; 9) any indication of leaf necrosis (LN) - foliage browning or burning; 10) number of primary inflorescences (PIs) - the inflorescences that are not accompanied by a true or transition leaf (Fig. 1);11) number of secondary inflorescences (SIs) - the inflorescences that are accompanied by a true or transition leaf; 12) inflorescence strength (IS) - a subjective rating of the strength of the flower stalk and stem, using the scale of $1=$ poor to $4=$ excellent; and 13) overall plant quality (PQ) - based on the following subjective scale: $1=$ poor-one flower or less, small shoots with very low floret number, leaf scorch, leaves above the flowers; $2=$ fair-one flower, minimal amount of leaf scorch, few florets, sparse foliage, and weak stems; 3 = good-one or two flowers, full foliar coverage of the pot, and relatively strong stems; and $4=$ excellent - three or more flowers, strong stems, full foliar coverage of the pot.

Data for the entire harvesting experiment were collectively tested by analysis of variance. Significant interactions required mean separation using least significant differences.

\section{Results}

Experiment 1. On arrival in the United States, multiflower inflorescences were clearly observed in all Dutch-grown cultivars (Fig. 2A). Crowns that were dissected during the 15 weeks of $2 \mathrm{C}$ storage commonly exhibited deterioration and flower abortion. In crowns with flower abortion, various fungi were also present. Subsequent to the abortions, reproductive meristems were reinitiated within 2 to 4 weeks. Abortion and reinitiation occurred during the preplanting period and in all cultivars examined. 
Two true leaves (compound) or a true leaf and a transition leaf were found at the base of the inflorescence in the reproductive meristems (Fig. 1). In the axil of the second true leaf or transition leaf, a panicle branch emerged. Panicle branches (secondary branches) that appeared above the last true leaf were subtended by a bract. The secondary branches were clearly observed (Fig. 2B). These branches developed acropetally in an alternate fashion around the main stem of the panicle. The secondary branches continued branching to form racemes (Fig. 3A) and a complete panicle structure was formed. Branches of the panicle branch were also subtended by bracts (Fig. 1). Florets located toward the base of the raceme were subtended by one large and two smaller bracts (Fig. 4A). As florets developed acropetally, the bract number became variable (Fig. 3B). Bract number decreased when the upper florets developed. Flowers did not develop beyond this stage during $2 \mathrm{C}$ storage.

On removal from $2 \mathrm{C}$ storage, the reproductive meristem continued to develop. Sepals appeared after floret bract development was complete (Fig. 4B). In all instances, five sepals were produced. Sepal formation was followed by the appearance of stamens in groups of five (Fig. 4C). After the first group was visible, a second set of five stamens formed before or simultaneously with five petals (Fig. 4D). At maturity, petals appeared small and narrow and very diminished compared to the sepals. The next reproductive organs formed were the carpels (Fig. $4 \mathrm{E}$ and F), which were variable in number. Usually two separate carpels (Fig. 5A) were
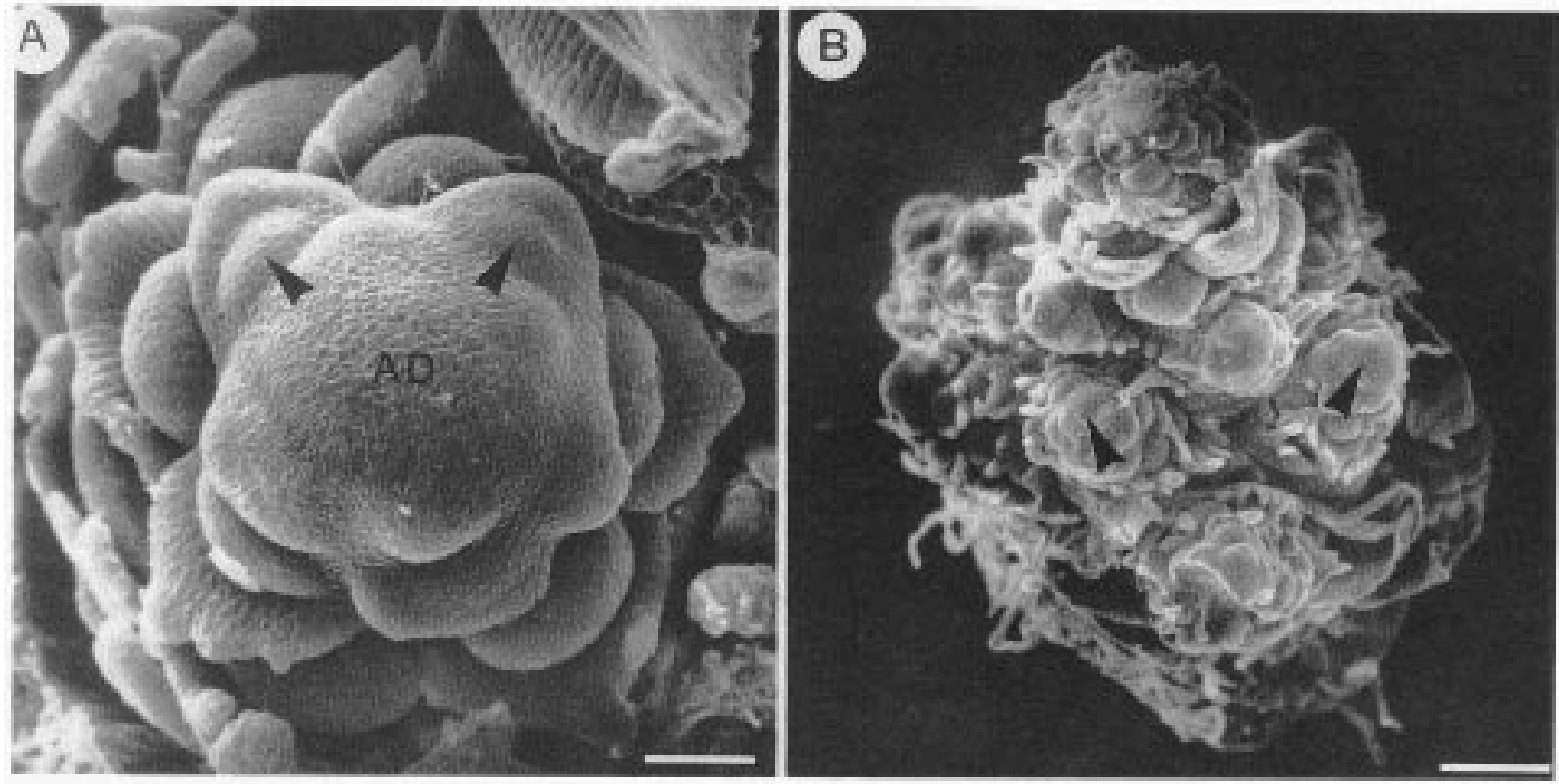

Fig. 2. (A) Astilbe inflorescence on arrival from The Netherlands and without cold storage. Developing secondary branches are identified with arrows. Bar $=50 \mu \mathrm{m}$. AD $=$ apical dome. (B) Development of the Astilbe inflorescence during 2C storage. Secondary branches are identified with arrows. Bar $=200 \mu \mathrm{m}$.
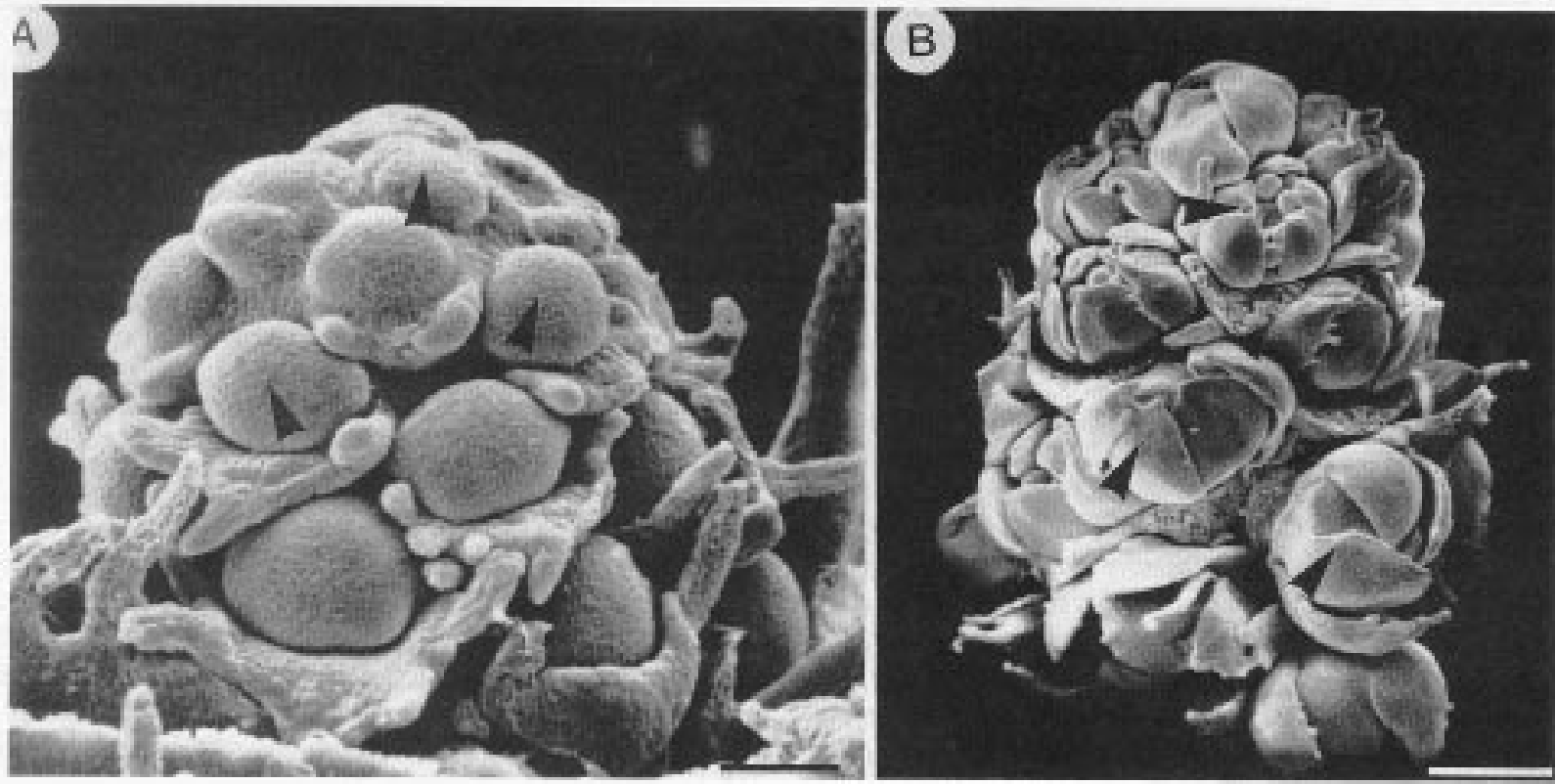

Fig. 3. (A) Astilbe raceme structure with florets (see arrows) in early bract-forming stages after $2 \mathrm{C}$ storage and immediately before planting. Bar $=100 \mu \mathrm{m}$. (B) Astilbe raceme structure with florets (see arrows) developed to gynoecium stage (see Fig. 4F) after 2 weeks of greenhouse forcing at 18 to $20 / 16$ to $18 \mathrm{C}$ (day/night). Bar $=200 \mu \mathrm{m}$. 

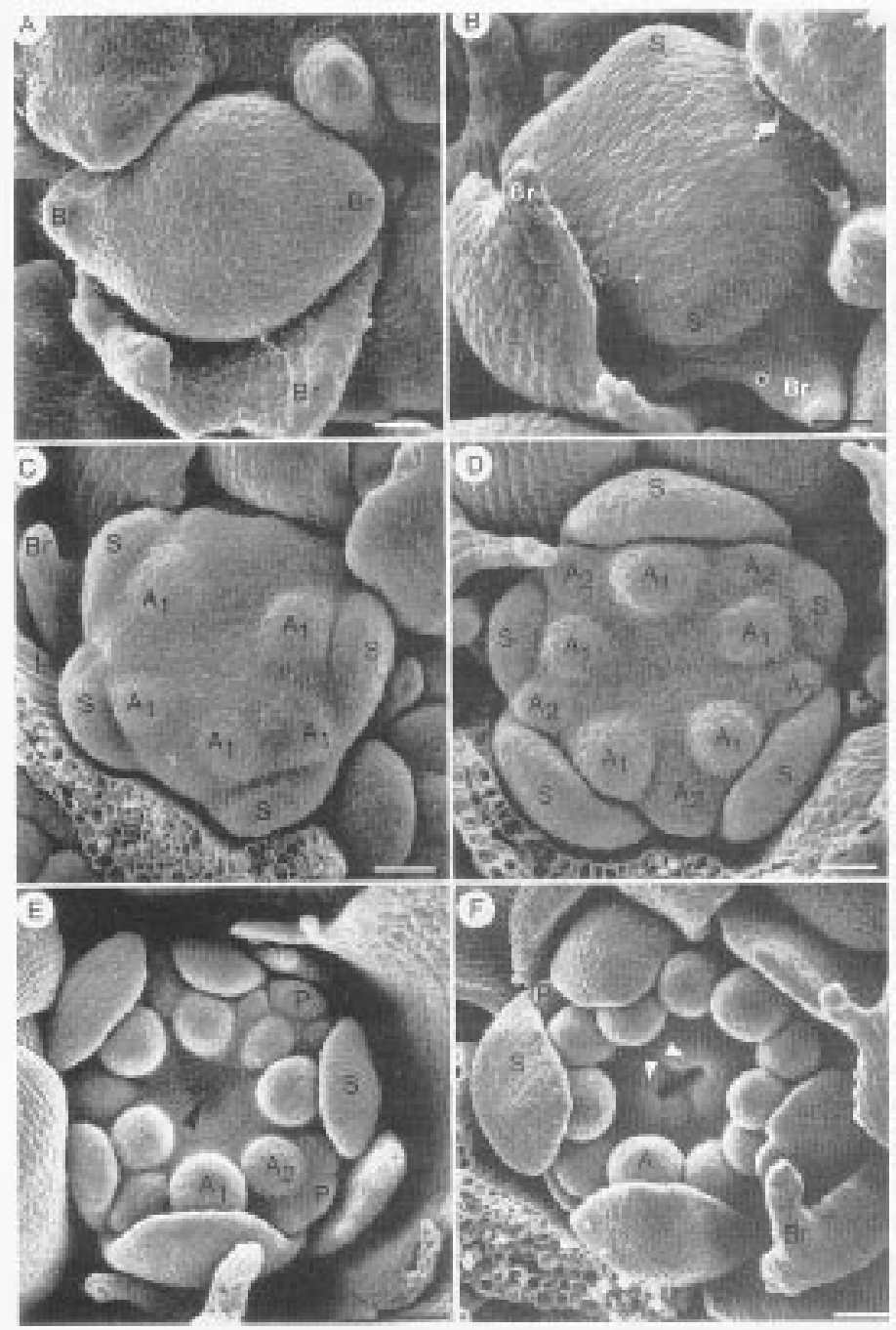

Fig. 4. Morphological development of a single floret of Astilbe. (A) Early bractforming stages. $\mathrm{Bar}=30 \mu \mathrm{m} . \mathrm{Br}=$ bract. (B) Early stages of the first whorl of perianth. $\mathrm{Bar}=30 \mu \mathrm{m} . \mathrm{Br}=$ bract and $\mathrm{S}=$ sepal. (C) Early stages of the first set of androecium. $\mathrm{Bar}=30 \mu \mathrm{m} . \mathrm{A}_{1}=$ first set of androecium, $\mathrm{Br}=$ bract and $\mathrm{S}=$ sepal (D) Early stages of the second set of androecium and second whorl of perianth. $\mathrm{Bar}=30 \mu \mathrm{m} . \mathrm{A}_{1}=$ first set of androecium, $\mathrm{A}_{2}=$ second set of androecium, and $\mathrm{S}$ $=$ sepal. $(\mathbf{E})$ Early stages of gynoecium (see arrow). Bar $=50 \mu \mathrm{m} . \mathrm{A}_{1}=$ first set of androecium, $\mathrm{A}_{2}=$ second set of androecium, $\mathrm{P}=$ petal, and $\mathrm{S}=$ sepal. $(\mathbf{F})$ Fully developed gynoecium (see arrow). $\mathrm{Bar}=40 \mu \mathrm{m} . \mathrm{A}_{1}=$ first set of androecium, $\mathrm{A}_{2}$ $=$ second set of androecium, $\mathrm{Br}=$ bract, $\mathrm{S}=$ sepal, and $\mathrm{P}=$ petal. seen; however, three carpels (Fig. 5B) were also observed. Observations of mature flowers indicated that Astilbe pistils were composed of a single carpel. The stigma were capitate supported by short styles.

Inspection of fully developed flowers showed variable organ numbers in the mature inflorescence. Several flowers contained structures that appeared to be undeveloped or juvenile stamens. In addition, petal and pistil number also varied. Petal numbers ranged from zero to five, while two to three pistils were common.

Experiment 2. Dutch-grown crowns harvested on 15 Oct. and 1 Nov. required the fewest days to reach MS of floral development (Table 1). If crowns were harvested before or after these dates, day to reach MS significantly increased. In general, crowns harvested on 15 Oct. also required less time to reach the FF stage of development (Table 1). For 'Bumalda' and 'Europa', however, there was no significant difference in time to reach FF for any harvest date (Table 2).

TPH, IH, and LH increased when crowns were harvested after 1 Oct. (Table 1). Greatest TPH with 'Europa' and 'Federsee' was obtained when harvested on 1 Oct. and 15 Oct., respectively (Table 2).

Overall, the most PIs and SIs were produced from crowns harvested on 15 Oct. (Table 1). With 'Bumalda', a significant increase in number of PIs occurred after 1 Oct., but no change was obtained in the number of SIs (Table 2). 'Europa' exhibited a similar increase in PIs and SIs after 1 Oct.; however, the number of PIs significantly decreased after 15 Oct. 'Federsee' produced the most PIs and SIs when harvested on 15 Oct. The number of PIs and SIs on crowns harvested before or after this date was significantly less. No similar relationships were obtained with 'Rheinland'. Even though PI and SI numbers were higher on 1 Oct. and 15 Oct. harvests, IL, IW, LN, and PD were unaffected (Table 1).

IS ranged from good to excellent (rating of 3-4) during the experiment for all cultivars except 'Federsee', for which a significant increase in IS occurred in plants harvested on 15 Oct. (Table 2).

The highest PQ was obtained when Astilbe crowns were harvested on 15 Oct. (Table 1). There was a significant decrease in PQ when plants were harvested before or after $15 \mathrm{Oct}$. PQ ranged from good to excellent (rating of 3-4) when crowns were harvested after 1 Oct. Crowns harvested as early as 15 Sept. resulted in fair-quality plants (rating of 2).
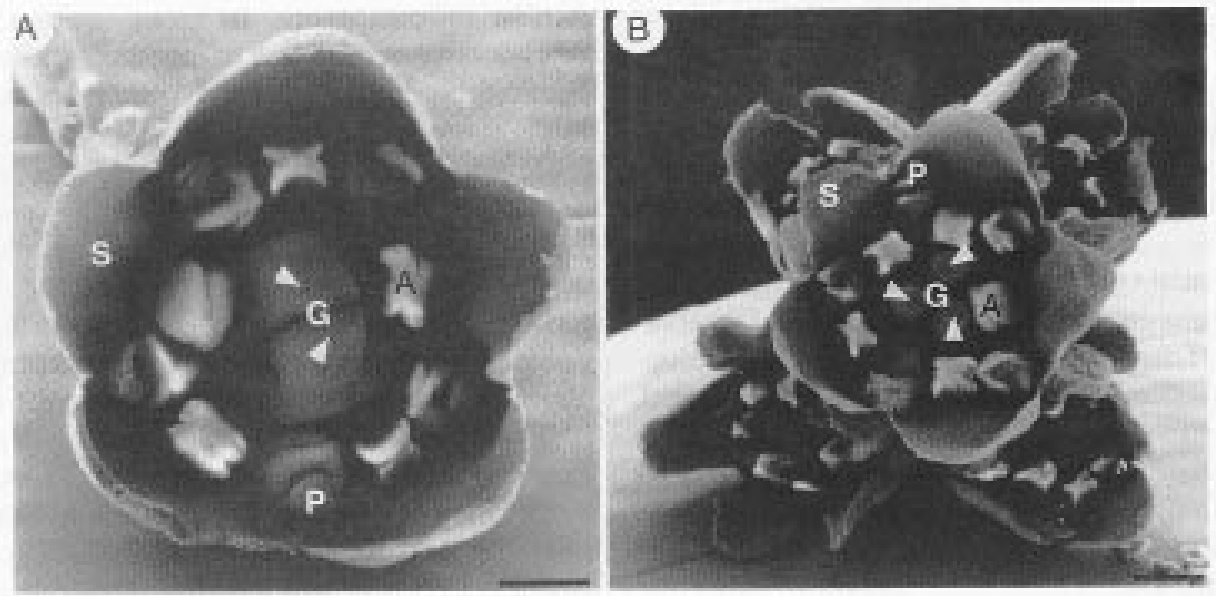

Fig. 5. (A) Astilbe floret from 'Fanal' with two separate pistils (arrows indicate the pistils). $B a r=300 \mu \mathrm{m} . \mathrm{A}=$ androecium, $\mathrm{G}=\mathrm{gynoecium}, \mathrm{P}=$ petal, and $\mathrm{S}=$ sepal. (B) Astilbe floret with three separate pistils (arrows indicate the pistils). $\mathrm{Bar}=400 \mu \mathrm{m}$. A = androecium, $\mathrm{G}=$ gynoecium, $\mathrm{P}=$ petal, and $\mathrm{S}=$ sepal. 
Table 1. Influence of five harvest dates on the forcing characteristics ${ }^{\mathrm{Z}}$ of Dutch-grown 'Bumalda', 'Europa', 'Federsee', and 'Rheinland' Astilbe in the United States.

\begin{tabular}{|c|c|c|c|c|c|c|c|c|c|c|c|c|c|}
\hline $\begin{array}{l}\text { Harvest } \\
\text { date }\end{array}$ & MS & FF & TPH & IH & LH & PD & IL & IW & LN & PI & SI & IS & PQ \\
\hline 15 Sept. & 46.77 & 53.25 & $32.50^{y}$ & 35.26 & 25.61 & 44.87 & 12.78 & 7.50 & 1.00 & 3.11 & 2.16 & 3.64 & 1.97 \\
\hline 1 Oct. & 47.67 & 55.33 & 40.71 & 42.08 & 29.64 & 50.57 & 15.64 & 9.72 & 1.00 & 8.15 & 2.60 & 3.56 & 3.10 \\
\hline 15 Oct. & 44.45 & 51.25 & 41.21 & 41.21 & 28.00 & 45.58 & 14.88 & 9.02 & 1.15 & 10.60 & 3.30 & 3.95 & 3.90 \\
\hline 1 Nov. & 45.00 & 53.95 & 37.20 & 37.12 & 27.13 & 45.34 & 13.70 & 8.77 & 1.00 & 5.95 & 1.45 & 3.70 & 3.02 \\
\hline 15 Nov. & 47.70 & 54.80 & 40.30 & 40.15 & 29.02 & 47.16 & 15.89 & 9.87 & 1.00 & 7.10 & 1.85 & 3.77 & 3.17 \\
\hline $\operatorname{LSD}_{(P \leq 0.05)}$ & 2.22 & 1.92 & 3.33 & 3.49 & 2.34 & 2.60 & NS & 1.20 & 0.09 & 1.64 & 0.95 & 0.29 & 0.38 \\
\hline
\end{tabular}

${ }^{\mathrm{z}} \mathrm{MS}=$ days to market stage (1 floret open); FF = days to full flower stage (90\% florets open); TPH = total plant height; IH = inflorescence height; LH = leaf height; $\mathrm{PD}=$ plant diameter; $\mathrm{IL}=$ inflorescence length; $\mathrm{IW}=$ inflorescence width; $\mathrm{LN}=$ leaf necrosis; $\mathrm{PI}=$ number of primary inflorescences; $\mathrm{SI}=$ number of secondary inflorescences; IS = inflorescence strength; PQ = plant quality.

yTPH is smaller than IH because these numbers represent averages of all plants in the treatment with or without inflorescences.

Table 2. Influence of five harvest dates in The Netherlands on the characteristics $^{\mathrm{z}}$ of four Astilbe cultivars in the United States.

\begin{tabular}{|c|c|c|c|c|c|c|}
\hline Cultivar & $\begin{array}{c}\text { Harvest } \\
\text { date }\end{array}$ & FF & TPH & PI & SI & IS \\
\hline \multirow[t]{5}{*}{ Bumalda } & 15 Sept. & 52.75 & 39.62 & 3.8 & 0.4 & 3.5 \\
\hline & 1 Oct. & 52.60 & 48.76 & 11.6 & 0.8 & 3.6 \\
\hline & 15 Oct. & 49.40 & 45.44 & 10.6 & 0.2 & 3.9 \\
\hline & 1 Nov. & 49.00 & 40.96 & 7.8 & 0.4 & 3.7 \\
\hline & 15 Nov. & 50.60 & 43.02 & 9.8 & 0.0 & 3.9 \\
\hline \multirow[t]{5}{*}{ Europa } & 15 Sept. & 52.33 & 29.62 & 2.2 & 1.5 & 3.7 \\
\hline & 1 Oct. & 52.60 & 43.30 & 13.2 & 5.4 & 3.9 \\
\hline & 15 Oct. & 50.80 & 42.42 & 15.0 & 4.0 & 4.0 \\
\hline & 1 Nov. & 51.00 & 37.16 & 7.8 & 2.4 & 3.9 \\
\hline & 15 Nov. & 51.60 & 44.14 & 10.8 & 3.8 & 3.9 \\
\hline \multirow[t]{5}{*}{ Federsee } & 15 Sept. & $---^{y}$ & 22.60 & 0.0 & 0.0 & --- \\
\hline & 1 Oct. & 67.67 & 34.38 & 0.8 & 0.8 & 2.2 \\
\hline & 15 Oct. & 55.00 & 41.38 & 8.4 & 3.8 & 4.0 \\
\hline & 1 Nov. & 59.80 & 34.20 & 4.0 & 1.0 & 3.3 \\
\hline & 15 Nov. & 64.00 & 36.26 & 1.8 & 1.4 & 3.3 \\
\hline \multirow[t]{5}{*}{ Rheinland } & 15 Sept. & 54.20 & 37.58 & 6.2 & 6.6 & 3.7 \\
\hline & 1 Oct. & 53.40 & 36.42 & 7.0 & 3.4 & 4.0 \\
\hline & 15 Oct. & 49.80 & 35.62 & 8.4 & 5.2 & 3.9 \\
\hline & 1 Nov. & 56.50 & 36.48 & 4.2 & 2.0 & 3.9 \\
\hline & 15 Nov. & 53.00 & 37.80 & 6.0 & 2.2 & 4.0 \\
\hline $\operatorname{LSD}_{(P \leq 0.05)}$ & & 3.84 & 6.65 & 3.3 & 1.9 & 0.6 \\
\hline
\end{tabular}

$\overline{\mathrm{z}} \mathrm{FF}=$ days to full flower (90\% florets open); TPH = total plant height; PI $=$ number of primary inflorescences; $\mathrm{SI}=$ number of secondary inflorescences; IS = inflorescence strength.

${ }^{y}$ No inflorescences were produced for this treatment, therefore, days to full flower and inflorescence strength could not be determined.

\section{Discussion}

Experiment 1. The presence of inflorescence structures (Fig. 2A) immediately after harvest is similar to the development of floral meristems of other perennials. The exact time of flowering initiation in Astilbe was not determined, but it may have occurred during July or August, after senescence of the previous season's inflorescences. Similar results of flower bud initiation with Paeonia lactiflora after anthesis were reported by Byrne and Halevy (1986). Floral development continued until all floral organs were fully formed, by the beginning of dormancy in the fall. Observations of the Astilbe floral meristems indicated that floral development was markedly repressed when ecodormancy was imposed. Floral initiation appeared to occur continuously. Lemattre (1971) also observed similar trends in bud development when studying 'Europa' and 'Fanal'. Initiation of the flower primordia occurred from September to December in buds $\geq 1 \mathrm{~cm}$ long and then bud development ceased until after Astilbe were forced.

The morphological structure of the panicle was clarified using SEM (Fig. 2 A and B). The overall structure can be described as a panicle of racemes with florets borne on tertiary branches.

Reproductive organs are usually initiated acropetally (centripetally) in order of sepals, petals, stamens, and carpels (Kinet et al., 1981). Basipetal (centrifugal) development has been identified for some organs. The centrifugal development of the Astilbe androecium observed after dissection was previously reported by Coulter and Chamberlain (1903). The change from acropetal to basipetal development resulted in the second whorl of androecium developing outside of the ring of the first whorl. Centrifugal initiation of stamens has been observed in 32 families (Kinet et al., 1981).

After greenhouse forcing was initiated, several unidentified floral structures were discovered in 'Fanal' (Fig. 4E). These structures may be juvenile stamens. Usually two or three unidentified structures were observed in a single floret. Since the structures were not present in all dissected florets, they can be considered morphological abnormalities. Abnormalities in the normal morphology of inflorescences and flowers can be attributed to genetic inheritance, suboptimal climatic conditions, or parasitism (Bernier et al., 1981; Meyer, 1966). Similar variations in Gypsophila paniculata inflorescence composition were observed when planting dates were changed from spring to summer (Hayashi et al., 1992). Bernier et al. (1981) listed the three most common abnormalities that are found in 1) inflorescence structure, i.e., increase or decrease in bract number, branch number, or both; 2) the flower structure, i.e., changed number of parts, fusion of normally free parts, or separation of normally fused parts; and 3) a developing axis, reproductive or vegetative, inside a flower, i.e., vegetative and reproductive proliferations. Stamens that were immature or not fully developed were observed in several mature Astilbe inflorescences. In many species, abortion of initiated reproductive organs due to incomplete development is common. An example of this arrested development would be the fifth stamen in the five-merous flowers of Digitalis (Bernier et al., 1981).

The pressure of multiple floret and organ formation in the developing meristem of the Astilbe inflorescence may be the cause for variable organ numbers observed in the mature florets. Since ecodormancy was imposed by subjecting the crowns to $2 \mathrm{C}$, this temperature may also contribute to abnormal inflorescence development. Further investigations to determine the cause of floral abnormalities in the Astilbe inflorescence are needed.

Experiment 2. De Hertogh and Le Nard (1993) stated that flower bulbs (geophytes) must reach a certain physiological state before they can flower. The ripeness to flower stage was reached 
after the juvenile period ended. Salisbury (1963) proposed that ripeness to flower was a matter of getting prepared to respond to photoperiod, synthesis of precursors, or both; enzymes; and pigment systems necessary for flowering. After the preparation period, the plants became sensitive to conditions that resulted in flower initiation.

Plants such as Biloxi soybean, kalanchoe, perilla, Chenopodium amaranticolor, annual hyoscamus, lolium, and Silene armeria do not have a true juvenile phase. However, during the early growth stages, these plants responded poorly to photoperiodic treatments. As plants age, sensitivity to daylength and cold increased to a maximum that can be maintained for a period of time.

Depending on the cultivar, the optimum harvest period for Dutch-grown Astilbe was from 1 Oct. to 1 Nov. Days to reach MS was minimized while TPH, IH, LH, and PIs and SIs were maximized during this period (Table 1). Crowns harvested during the 4week window had the highest overall plant quality and performed as physiologically mature crowns. Crowns harvested before the window took longer to reach MS of floral development and produced fewer inflorescences. Lemattre (1971) also reported a lower percentage of plants flowering and an increase in the number of days to flower from crowns harvested in September. Undifferentiated flower primordia may have led to plants that did not grow or had a low percentage of flowering. These Astilbe crowns may not have achieved the state of physiological maturity necessary to produce high-quality plants. Mahlstede and Fletcher (1960) reported that digging hollyhocks early impaired their keeping quality and reduced the field stands when replanted. As the plants matured, the amount of water contained in each plant gradually decreased. Field survival was correlated with the amount of water in the plant tissues before the first killing frost.

Roberts et al. (1978) found that delaying harvest of Lilium longiflorum from July to October produced plants with higher harvest maturity index ratings. These ratings were based on harvest date, bulb weight, and the number of scale and leaf primordia of the daughter bulbs. Easter lilies with larger bulbs and more daughter leaf primordia had earlier shoot emergence and flowering when grown under standard forcing programs. However, bulbs receiving a lower rating could be forced if the forcing program was modified.

Astilbe crowns harvested after the 4-week window had matured beyond the optimum physiological state for forcing. The number of days to reach MS of development increased and PI and SI numbers declined (Table 1). Lemattre (1971) harvested Astilbe from September to February and exposed the crowns to hot water vapor at $44 \mathrm{C}$ for 1 to $3 \mathrm{~h}$. The number of days required for flowering significantly increased when crown harvest was delayed from October to November. However, the number of flowering stalks per plant did not decrease until harvest was delayed until January or later. Similar trends were observed in Gypsophila paniculata when planting dates changed from spring to summer (Hayashi et al., 1992). Days to flowering, inflorescence fresh weight, stem length, number of nodes, number of primary and secondary branches, and number of florets tended to decrease. However, in terms of units, fresh weight, diameter of the inflorescence unit axis, the highest order of visible florets, and number of florets tended to increase.

Plant size or maturity was a determining factor for flowering of Aquilegia (columbine) (Shedron and Weiler, 1982; White et al., 1990; Zhang et al., 1991). When plants were exposed to low temperatures at a very young stage of development (six-leaf stage), they did not respond to the low temperatures; whereas, mature plants (17 leaf stage) required fewer cold weeks to flower. With columbine, plants must produce a minimum number of leaves before cold treatments can reduce forcing time.

Due to different climatic conditions, bulbs grown in various areas of the world are at different physiological states when harvested. This difference is a direct result of exposure to different soil temperatures before harvest. Hence, when these bulbs are forced, they will react differently to the same treatments (Sano, 1975). Studies are needed to identify morphological markers, physiological markers, or both for Astilbe so that only mature crowns are harvested. Mature crowns must be identified for forcing and for garden markets, since flowering is expected from the marketable crowns.

\section{Literature Cited}

Bailey, L.H. 1935. Standard cyclopedia of horticulture. Macmillan, New York. p. 422-423.

Bernier, G., J. Kinet, and R.M. Sachs. 1981. The physiology of flowering. vol. 1. CRC Press, Boca Raton, Fla.

Byrne, T.G. and A.H. Halevy. 1986. Forcing herbaceous peonies. J. Amer. Soc. Hort. Sci. 111:379-383.

Chittenden, F.J. and P.M. Synge (eds.). 1956. The royal horticultural society dictionary of gardening. Clarendon, Oxford, England. p. 215-216.

Coulter, J.M. and C.J. Chamberlain. 1903. Morphology of angiosperms. D. Appleton and Co., New York.

De Hertogh, A.A. and M. Le Nard (eds.). 1993. The physiology of flower bulbs. Elsevier Science, Amsterdam, The Netherlands.

Hartsema, A.H. 1961. Influence of temperatures on flower formation and flowering of bulbous and tuberous plants, p. 135-141. In: W. Ruhland (ed.). Handbuch der Pflanzenphysiologie. vol. 16. Springer-Verlag, Berlin.

Hayashi, T., H. Miyata, and K. Konishi. 1992. Inflorescence development and composition of Gypsophila paniculata L. 'Bristol Fairy'. J. Jpn. Soc. Hort. Sci. 61:135-141.

Kinet, J., R.M. Sachs, and G. Bernier. 1981. The physiology of flowering. vol. 3. CRC Press, Boca Raton, Fla.

Latta, R. and C.F. Doucette. 1932. Insect control stimulates growth. Florists' Rev. 70:11-13.

Lemattre, P. 1971. Action d'un traitement thermique sur la dormance des astilbes. Ann. Ameliores Plantes 21:125-139.

Liberty Hyde Bailey Hortorium. 1976. Hortus third: A concise dictionary of plants cultivated in the United States and Canada. 3rd ed. Macmillan, New York. p. 125-126.

Mahlstede, J.P. 1956. Effect of season of digging on the survival hybrid tea roses in storage and in the field. Iowa Nurseryman's Res. Rpt.

Mahlstede, J.P. and W.E. Fletcher. 1960. Storage of nursery stock. Amer. Assn. Nurserymen, Washington, D.C.

Meyer, V.G. 1966. Flower abnormalities. Bot. Rev. 32:165-195.

Post, K. 1959. Florist crop production and marketing. Orange Judd, New York. p. 339-341.

Radford, A.E., H.E. Ahles, and C.R. Bell. 1964. Manual of the vascular flora of the carolinas. Univ. of North Carolina Press, Chapel Hill. p. 523-525.

Roberts A.N., J.L. Green, and F.W. Moeller. 1978. Lily bulb harvest maturity indices predict forcing response. J. Amer. Soc. Hort. Sci. 103:827833.

Salisbury, F.B. 1963. The flowering process. Pergamon, New York.

Sano, Y. 1975. The effects of light and bulb composition on the growth and flowering of iris 'Wedgwood'. J. Jpn. Soc. Hort. Sci. 44:66-72.

Shedron, K.G. and T.C. Weiler. 1982. Regulation of growth and flowering in Aquilegia $\times$ hybrida Sims. J. Amer. Soc. Hort. Sci. 107:878-882.

White, J.W., H. Chen, X. Zhang, D.J. Beattie, and H. Grossman. 1990. Floral initiation and development in Aquilegia. HortScience 25:294-296.

Zhang, X., J.W. White, and D.J. Beattie. 1991. Regulation of flowering in Aquilegia. J. Amer. Soc. Hort. Sci. 116:792-797. 